Submitted to Journal of Fluid Engineering

\title{
Aerodynamic Study of a Tricycle Wheel Sub-System for Drag Reduction
}

\author{
Thomas Driant $^{1}$, Lakhdar Remaki ${ }^{2}$, Hachimi Fellouah ${ }^{1} *$, Stéphane Moreau ${ }^{1}$, Alain \\ Desrochers $^{1}$ \\ ${ }^{1}$ Department of mechanical engineering \\ Université de Sherbrooke \\ 2500, Boulevard de l'Université, Sherbrooke, QC, Canada \\ ${ }^{2}$ Basque Center for Applied Mathematics (BCAM) \\ Mazarredo, 14. 48009 Bilbao Basque Country, Spain
}

*Corresponding author: Hachimi.Fellouah@,USherbrooke.ca 


\begin{abstract}
This paper deals with a CFD and experimental drag analysis on an isolated rotating wheel subsystem (including its accessories: tire, suspension, A-arms and fender) of a motor tricycle vehicle with two wheels in front. The main goal of the present work is to study the effect of the fender on the wheel subsystem drag and its optimization. The Star CCM+ commercial code was used for the numerical simulations. Different flow conditions were simulated and some results were validated by comparison to wind tunnel experimental results. To perform drag optimization, several aerodynamic fender shapes were designed and simulated as part of the sub-system. A drastic drag reduction up to 30.6\% compared to the original wheel sub-system was achieved through numerical simulations.
\end{abstract}

\title{
1. Introduction
}

The need to protect the environment and improve fuel efficiency has pushed aerodynamics toward the top of the automakers' priority lists. Also as fuel prices are increasing, vehicle owners are becoming more concerned about the gas mileage of their vehicles.

Several solutions are likely to effectively reduce the energy consumption of a vehicle: reducing its mass, increasing its engine performance, reducing its rolling resistance drag, and optimizing the airflow around the vehicle to reduce aerodynamic drag. Some of these solutions are complex to implement on small vehicles. In fact, based on an in-house study conducted on motor tricycle vehicle with two wheels in front (the same vehicle considered in the present study) [1], reducing $50 \mathrm{~kg}$ in the vehicle weight will provide a $3 \%$ reduction in fuel consumption. However this solution requires a new study of the vehicle behavior (geometry, balance, ligther material) and entails an increase in cost. Increasing the engine performance is also costly for a 
production vehicle. Reducing the aerodynamic drag has become an important improvement avenue since it allows increasing the fuel economy of the vehicle without adding any weight or without introducing any expensive technologies $[2,3]$. Moreover, the internal study also showed a dissipation force distribution in a World Motorcycle Test Cycle (WMTC) of $32 \%$ for the rolling resistance drag and $68 \%$ for the aerodynamic vehicle total drag. Some aerodynamic studies on different vehicles were completed on simplified geometries, like Ahmed body or simplify truck [4-7]. As a consquences of these simplications, some flow details inherent to the geometry complexity are ignored, particularly the flow interaction between the different parts. In fact these simplications will not alter the broad lines of the vehicle aerodynamic shape design.

According to Barlow's review [8] and confirmed by our present tests, the tricycle wheel subsystem (Fig 1a) contributes to one third of the vehicle total drag. The aerodynamic design of this subsystem has a major role in the overall design of the vehicle. This motivates our study to focus on the aerodynamic optimization of this part. The air flow past the wheel sub-system is complex as it is characterized by the formation of large vortices in both the vertical and lateral planes inducing drag. Understanding the dynamics of these vortices is thus very important for the design of an efficient aerodynamic vehicle. Moreover, and to our knowledge, the proposed study is the first aerodynamic simulation and experiment on the whole wheel sub-system including the effect of the wheel fender. The literature review shows, however, some detailed studies of an open rotating wheel of a formula 1 racing car [10-14].

In the present study, numerical simulations are performed, using the Star CCM+ commercial code, for different operating conditions on a standard wheel sub-system geometry of a motor tricycle vehicle (whith 2 wheels in front). Several aerodynamic shapes of the fender are designed and tested in the wind tunnel, located at the Université de Sherbrooke, following a strategy that is 
described below. A drastic drag decrease of up to $30 \%$ of the original wheel sub-system installed on the present vehicle is obtained.

\section{Construction and validation of the model}

To reach the resent paper objective, a numerical model was first developed for the stock version (reference version) of the tricycle. CATIA (V5R18) software is used to create a CAD model and then STAR CCM+ is used to generate the mesh and perform simulations. The stock version and its CAD model are shown in Fig 1. The numerical and experimental methodologies developed in this study are well detailed in Driant et al. $[9,15]$. In this section, only a summary is given.

For the grid, hexahedral elements are used in all present simulations for their accuracy and better rate of convergence. A volume mesh refinement near the wheel (Fig 2) is adopted here. Based on the drag over the wheel (Fig 3), 9 million elements are used for the simulation as they provide a good balance between accuracy and processing time. Five prismatic layers are generated ensuring that the viscous length scale to the wall (the dimensionless wall distance), $\mathrm{y}^{+}$, remain within the range of 30 to 50 (within the log-layer).

The full three-dimensional Reynolds-Averaged Navier-Stokes equations are solved with a second-order spatial scheme for velocity and pressure, and a first-order scheme for the turbulent variables. For the RANS closure, three turbulent models were tested, the realizable K- $\varepsilon$, the K- $\omega$ and the K- $\omega$ SST models along with the use of wall functions. All present simulations have been stopped after the residuals had dropped by four orders of magnitude. Even if the flow is largely three-dimensional and often separated in such a complex vehicle geometry, close results have been obtained from these models with a discrepancy on drag that is less than $3 \%$ as shown in Fig 
4. Therefore, based on the computational cost and best convergence rate, the realizable K- $\varepsilon$ turbulent model was retained for the present simulation.

In the experiments, an electrical motor with an electronic speed controller is used to control and maintain the wheel rotational speed (see Fig 1a). The exact same set-up is modeled. The rotating wheel is simulated by a boundary condition approach by imposing a constant tangential velocity as a boundary condition. This method gives similar drag prediction (about $1 \%$ error) as the experimental result (Table 1) and less computing time than the more physically consistent multiple-reference frame (frozen-rotor) approach, which was also found in [16].

For the experimental validation of the numerical model, the stock version of the tricycle is installed in the $1.82 \mathrm{~m} \times 1.82 \mathrm{~m}$ section of the "S1 wind tunnel", located at Université de Sherbrooke (Fig 1b). No rotating ground is available in such a test facility. The test section is 10 $\mathrm{m}$ long and the wind is generated by a $1.8 \mathrm{~m}$ diameter vane axial fan driven by a $200 \mathrm{hp}$ electric motor. The rotational speed of the fan, and consequently the wind speed in the test section, can be varied using a variable frequency controller drive. The top air velocity in the empty $1.82 \mathrm{~m} \times 1.82$ $\mathrm{m}$ test section is $30 \mathrm{~m} / \mathrm{s}$. The velocity profile was measured to be uniform within $\pm 1 \%$ except near the wall where the boundary layer has a thickness in the order of $5 \mathrm{~cm}$. The level of turbulence is less than $0.3 \%$.

The three components of the air loads (drag, lift and pitching moment) are measured using a wind tunnel balance designed at Université de Sherbrooke, sketched in Fig 5. The balance is isolated from the airflow during the measurements; as shown in Fig 1b, and calibrated regularly between tests. It is designed to support the wheel sub-system and its dynamic stress. The $C_{d}$.A coefficient is then estimated by equation (1). 


$$
F=\frac{1}{2} \cdot \rho_{a h} \cdot C_{d} \cdot A \cdot V^{2}
$$

Atmospheric conditions were recorded at the beginning and at the end of each test in order to measure the air density accurately. This was done according to Equation (2) (see [17] for more details).

$$
\rho_{a h}=\frac{p \cdot M_{a}}{Z \cdot R \cdot T}\left[1-x_{v} \cdot\left(1-\frac{M_{v}}{M_{a}}\right)\right]
$$

The wall pressure on upper and lower side of the wheel fender is measured using five piezoelectric differential pressure transducers of \pm 1 psi (Honeywell Sensing and control, SX01DD4, accuracy: $0.2 \%$ max full scale span, its differential pressure range: 0 to $1 \mathrm{psi}$ ). The pressure measurement points are located in a plane shifted five centimeters away from the fender longitudinal plane as shown in Fig 6. The pressure reading is made between the experimental points (wall pressure) and the static pressure point of the Pitot probe installed inside the wind tunnel. The accuracy of the pressure coefficient thus measured is about \pm 0.05 .

The output signal (the pressure transducers and load cells gauges) is digitized using an E-Daq acquisition data logger with an integrated run-time display for real-time tests. The time traces were recorded at a sampling frequency of $50 \mathrm{~Hz}$ during 90 seconds. The experiments were conducted for the rotated wheel factory fender (Fig 1). A Fast Fourier Transform (FFT) was applied to the acquired time-series of the instantaneous data to control the resonance frequencies. Noise in the spectrum was reduced by employing a moving average filter. The experimental results obtained for the rotated wheel factory fender are shown in Table 1. 
Two air speeds were considered both experimentally and numerically: $U_{0}=20 \mathrm{~m} / \mathrm{s}$ and $27.7 \mathrm{~m} / \mathrm{s}$

which corresponds to Reynolds number, based on the wind tunnel width, $R e_{W}=\frac{\rho_{a h} U_{0} w}{\mu}$, of 2.4 $\times 10^{6}$ to $3.4 \times 10^{6}$. Note that the ratio between the tangential rotating velocity at the circumference of the wheel and the free-stream velocity is kept equal to one in all simulations. The numerical model reflects the experimental set-up faithfully; the wheel subsystem is simulated as installed in the above test section of wind tunnel $(1.8 \mathrm{~m} \times 1.8 \mathrm{~m} \times 10 \mathrm{~m})$. The frontal area of the present wheel sub-system; tire of external diameter $\mathrm{D}=0.57 \mathrm{~m}$ and accessories, is close to $0.12 \mathrm{~m}^{2}$, which gives a frontal blockage effect of $3.6 \%$ and a range of Reynolds number based on the tire diameter, $R e_{D}=\frac{\rho_{a h} U_{0} D}{\mu}$, from $7.5 \times 10^{5}$ to $1.1 \times 10^{6}$.

The pressure coefficient distribution on the lower and upper surfaces of the stock fender used in the present study is given in Driant et al. [9] and shown in Fig 7Fig 7. This figure confirms the good agreement between the numerical model adopted here and experimental result which reinforces the reliability of the present numerical model. The result shows that the section in front of the wheel has higher static pressure and the gap between the wheel and the fender causes a depression that is represented by the negative static pressure in Fig 7 . The large vortices in the buck fender lead to negative static pressure. The positive region in the lower side of the fender is caused by the wheel rotation that brings the flow in the gap between the wheel and the fender.

\section{Drag optimization through geometrical consideration}

The CFD model being validated against experimental data with success is applied to the wheel sub-system drag optimization by designing new fender geometries and comparing the new drag force to the reference one generated by the stock version. The fender is chosen as a first target for 
the whole wheel sub-system optimization because it has the largest contribution to the total drag as seen in Fig 8 that provides the drag contribution of each part.

This pie-chart clearly points out that the fender is the most important contributor to the total drag followed by the A-Arms. This strong contribution could be explained by the size, shape and the position of the fender in the flow direction that were driven by the style of the stock tricycle. The gap between the tire and the fender also creates some kind of "duct" that accelerates the air flow thus creating a Venturi effect. The circular shaped fender acts like a "parachute", which generates a significant pressure increase on its internal face. The rim spokes also stir air when the wheels are rotating and therefore increasing the resistance to the flow. The current fender shape cannot prevent this behavior. Consequently, the objective of this study is to mostly reduce the drag caused by the fender.

The flow topology in the CFD around the stock wheel subsystem shows that the flow is complex; a huge recirculation zone exists at the back of the subsystem (its length being slightly greater than a tire diameter) and an important stagnation zone appears on its front (Figs. 9 and 10). The important recirculation areas seen in the velocity contours have a large contribution to the drag increase. The velocity vectors stress the complex flow topology in the recirculation area.

As an important source of strong vortices and high pressure, the back and front of the fender are clearly worth improving to reduce the total drag. Keeping in mind that this is still a complete vehicle downstream of the wheels, the reduction in vortices will also have an important impact on the vehicle total drag and the pilot wind comfort.

Consequently, the important recirculation zones of the flow behind the wheel should be limited. To reduce the high pressure created by the fender, one solution is to extend it towards the 
ground beyond the front pressure stagnation point. The flow needs to be kept attached to the fender as well, which suggests the design of a completely closed wheel as shown in Fig 11.

Numerical results on such a design show a drag reduction of $23 \%$ of the subsystem total drag. However these results show that the flow is still separated from the rear part of the fender. In order to reduce the recirculation zone and reattach the flow, the fender is extended in the back by adding a long tail as shown in Fig 12. The velocity vectors field of the flow around the subsystem in Fig 13, no longer shows any recirculation area and the flow is now completely reattached.

Because of practical constraints on the vehicle, the fender back tail length needs to be shortened. Moreover, an important ground effect caused by the reduced space between the fender and the ground is observed in Fig 13. To overcome these shortcomings, a geometrical modification called the "boat tailing" optimization technique [18] that consists in a gradual reduction of the body cross section has been applied to optimize the flow pattern around the body. The "boat tailing" technique is used for many road vehicles from bluff bodies to complex road vehicles, [19-21]. In the present study, this technique is applied vertically (fender tail) and horizontally (fender bottom). Four horizontal and three vertical sections of equal distances are performed as shown in Fig 14.

The "boat tailing" optimization technique allowed the determination of the optimal fender/ground distance and the optimal fender tail length. The result is shown in Fig 15 (see Fig 14 for the positions). From the two graphs, it is clear that the horizontal cut at the section 3 and the vertical position cut at the section 3 show a low drag on the wheel subsystem. Of course, the combination of horizontal and vertical position was tested to obtain the most efficient fender. The optimal configuration of the fender shape represents the minimum drag on the wheel subsystem. Fig 16 shows the velocity magnitude contours of the flow around the closed version of the 
optimized fender geometry and the optimized fender obtained by the boat tailing optimization technique (applied horizontally and vertically).

The result obtained here shows that with this new improvement (Fig 16b), the drag wheel subsystem is reduced by about $30.6 \%$. This result demonstrates the importance of reducing the interaction between the fender and the ground.

Moreover the suspension system on the stock version shows that the fender, the A-arms shape and the deflectors generate large vortices as shown in Fig 17a. With the optimization obtained in the present work (fender only), a noticeable vortex reduction is obtained around the wheel as well (see Fig 17b). Note that the tangential velocity is computed in the global reference frame (the free-stream is accounted for). Figure 17 shows that some vortices remain present; they are generated by different interactions between the wheel subsystem such as the fender/suspension interaction or the A-arm/suspension interaction and the ground/fender/rotating wheel interaction.

\section{Conclusion}

This paper has proposed an efficient process to reduce drag on a tricycle vehicle through an aerodynamic optimization of the wheel fender. Numerical simulations of the flow past the system have been performed using the commercial Navier-Stokes solver, Star CCM+. Wind tunnel tests were achieved to validate the model.

A new fender shape was proposed in the present study that reduces the wheel subsystem drag by about $30.6 \%$ compared to the subsystem stock version. Vortices and recirculation zone were reduced at the back of the wheel subsystem (near wake) and between the subsystem parts. The resulting optimization reduces the aerodynamic losses and consequently the drag as demonstrated 
by the numerical simulations. As such, the new shape will also improve the tricycle vehicle pilot comfort.

With the optimization achieved in the present work (concerning the fender only), a noticeable vortex reduction is obtained around the wheel. However, some vortices caused by the presence of the other parts of the sub-system (A-arms shape and the deflectors) remain present and generate noticeable drag. More tests should be undertaken to optimize the A-Arms and the deflectors.

\section{Acknowledgments}

The authors would like to thank the Natural Sciences and Engineering Research Council (NSERC) of Canada for their financial support.

\section{References}

[1] Mogenot, Y., Tacher, M., Desrochers, A., Maslouhi A., Quiron P., 2012, "Weight saving methodology and application to an hybrid roadster", Electric Vehicle EV conference (EV2012VÉ), Montreal, Canada, pp. 71-80.

[2] Lutsey, N., and Sperling, D., 2005, "Energy Efficiency, Fuel Economy, and Policy Implications" Transportation Research Board of the National Academies, 1941/2005.

[3] Bachman, L. J., Erb, A., and Bynum, C. L., 2005, "Effect of Single Wide Tires and Trailer Aerodynamics on Fuel Economy and NOx Emissions of Class 8 Line-Haul Tractor-railers," SAE International, 05CV-45.

[4] Ahmed, S. R., 1983, "Influence of Base Slant on the Wake Structure and Drag of Road Vehicles," J Fluids Eng- Trans ASME, 105(4) pp. 429-434.

[5] Krajnovic, S., and Davidson, L., 2005, "Flow Around a Simplified Car, Part 1: Large Eddy Simulation," J Fluids Eng- Trans ASME, 127(5) pp. 907-918. 
[6] Krajnovic, S., and Davidson, L., 2005, "Flow Around a Simplified Car, Part 2: Understanding the Flow," J Fluids Eng- Trans ASME, 127(5) pp. 919-928.

[7] Roy, C. J., Payne, J., and McWherter-Payne, M., 2006, "RANS Simulations of a Simplified Tractor/Trailer Geometry," J Fluids Eng- Trans ASME, 128(5) pp. 1083-1089.

[8] Barlow, J., Rae, W., and Pope, A., 1999, "Low Speed Wind Tunnel Testing," (3rd edition).

[9] Driant, T., Fellouah, H., Moreau, S., Desrochers, A., Remaki, L., 2013, "Numerical simulation and wind tunnel measurements on a tricycle wheel sub-system". Int. J. Eng. Sys. Modelling and Simulation, 5, pp. 159-167.

[10] McManus, J., and Zhang, X., 2006, "A Computational Study of the Flow Around an Isolated Wheel in Contact with the Ground," J Fluids Eng- Trans ASME, 128(3) pp. 520-530.

[11] Van Den Berg, M. A., and Zhang, X., 2009, "The Aerodynamic Interaction between an Inverted Wing and a Rotating Wheel," J Fluids Eng- Trans ASME, 131(10) pp. 101104110110413.

[12] Kellar, W. P., Pearse, S. R. G., and Savil, A. M., 1999, "Formula 1car Wheel Aerodynamics," Sport Eng., pp. 203-212.

[13] Wäschle, A., Cyr, S., Kuthada, T., 2004, "Flow Around an Isolated Wheel-Experimental and Numerical Comparison of Two CFD Codes," SAE International, Vol 2004-01-0445.

[14] Saddington, A. J., Knowles, R. D., and Knowles, K., 2007, "Laser Doppler Anemometry Measurements in the Near-Wake of an Isolated Formula One Wheel," Exp. Fluids, 42(5) pp. 671-681.

[15] Driant, T., Fellouah, H., Moreau, S., Desrochers, A., Remaki, L., July 2012, “Aerodynamic study of a hybrid tricycle wheel sub-system for drag reduction", ASME conference (American Society Of Mechanical Engineers), Rio Grande, Puerto Rico, USA. 
[16] Karabelas, S. J., and Markatos, N. C., 2012, "Aerodynamics of Fixed and Rotating Spoked Cycling Wheels," J Fluids Eng- Trans ASME, 134(1).

[17] Davis, R. S. 1992, "Equation for the Determination of the Density of Moist Air (1981/91)", Metrogia 1992, 29(1), pp. 67-70.

[18] Mair, W. A., 1969, "Reduction of Base Drag by Boat-Tailed After bodies in Low Speed Flow," Aeronautical Quaterly, 20, pp. 307-320.

[19] Hucho, W. H., 1998, "Aerdynamic of Road Vehicles," (Fourth Edition), SAE International.

[20] Muyl, F., Dumas, L., and Herbert, V., 2003, "Hybrid Method for Aerodynamic Shape Optimization in Automotive Industry," Computers and Fluids.

[21] Verzicco, R., Fatica, M., Iaccarino, G., 2002, "Large Eddy Simulation of a Road Vehicle with Drag-Reduction Devices," AIAA, 40(12). 


\section{Nomenclature}

A: $\quad$ Frontal area

$C_{d}: \quad$ Drag coefficient

$F: \quad$ Drag force

$M_{a}:$ Dry air molar mass

$M_{v}:$ Water molar mass

$p$ : Absolute pressure

$R: \quad$ Specific gas constant

T: $\quad$ Temperature

$\mathrm{V}_{0} \quad$ Free stream flow velocity in the wind tunnel

$V$ : Local flow velocity

$x_{v}: \quad$ Water vapor mass fraction

Z: $\quad$ Compressibility factor

$\rho_{a h}:$ Air density with temperature and humidity correction

$\mu \quad$ Air viscosity 


\section{List of tables}

Table 1: Numerical and wind tunnel results comparison 


\section{List of figures}

Fig 1: The wheel sub-system. a) CAD design for simulation and tests, b) installed in the wind tunnel (Driant et al. [9])

Fig 2: Wheel mesh section view (Driant et al. [9])

Fig 3: Drag variation with number of mesh elements (Driant et al. [9])

Fig 4: Drag value for experimental results and different turbulent models

Fig 5: Aerodynamic balance design (Driant et al. [9])

Fig 6: Pressure taps positioning (Driant et al. [9])

Fig 7: Fender pressure coefficient (Cp) comparison. a) Lower side $\mathrm{Cp}$, b) Upper side Cp. Symbol: experimental measurements, solid line: numerical results. See Fig 6 for angle reference. (Driant et al. [9])

Fig 8: Contribution of the wheel sub-system parts to the drag

Fig 9: Velocity magnitude contours of the flow around the stock wheel subsystem delimiting the recirculation area.

Fig 10: Velocity vector field of the flow around the stock wheel subsystem showing the flow topology in the recirculation area

Fig 11: Enveloping fender

Fig 12: Closed version of the optimized fender geometry

Fig 13: Velocity vector field of the flow around the optimized fender

Fig 14: The "boat tailing" optimization technique, definition of the section.

Fig 15: The optimal fender shape obtained by the boat tailing optimization technique. (a) fender/ground distance optimization and (b) fender tail optimization 
Fig 16: Velocity magnitude contours on an optimized version. (a)Closed fender version, (b) Optimized version obtained by the boat tailing technique

Fig 17: Front view of tangential velocity vector (global reference) along longitudinal section $\mathrm{x}=-$ $600 \mathrm{~mm}$ ( 1 wheel Diameter); origin is on the wheel hub. (a) Stock version, (b) Optimized fender 


\begin{tabular}{|c|c|c|c|c|}
\hline \multirow{2}{*}{$\begin{array}{c}\text { Flow speed } \\
(\mathrm{m} / \mathrm{s})\end{array}$} & Experimental results & \multicolumn{2}{|c|}{ CFD results } & \multirow{2}{*}{$\begin{array}{c}C_{d} \cdot A \text { Error } \\
(\%)\end{array}$} \\
\cline { 2 - 5 } & $\begin{array}{c}C_{d} \cdot A \\
\left(\mathrm{~m}^{2}\right)\end{array}$ & $\begin{array}{c}\text { Boundary } \\
\text { condition }\end{array}$ & $\begin{array}{c}C_{d} \cdot A \\
\left(\mathrm{~m}^{2}\right)\end{array}$ & 1.45 \\
\cline { 2 - 5 } 20 & $\begin{array}{c}0.154 \\
\pm .002\end{array}$ & $\begin{array}{c}\text { Tangential } \\
\text { velocity }\end{array}$ & 0.157 & 0.87 \\
\hline \multirow{2}{*}{27.7} & $\begin{array}{c}0.154 \\
\pm .002\end{array}$ & $\begin{array}{c}\text { Frozen rotor } \\
\text { Tangential } \\
\text { velocity }\end{array}$ & 0.153 & 3.32 \\
\hline \multicolumn{2}{|l|}{ "The "frozen rotor" method in the present study refers to the multiple reference frame approach } \\
\hline
\end{tabular}

Table 1: Numerical and wind tunnel results comparison 

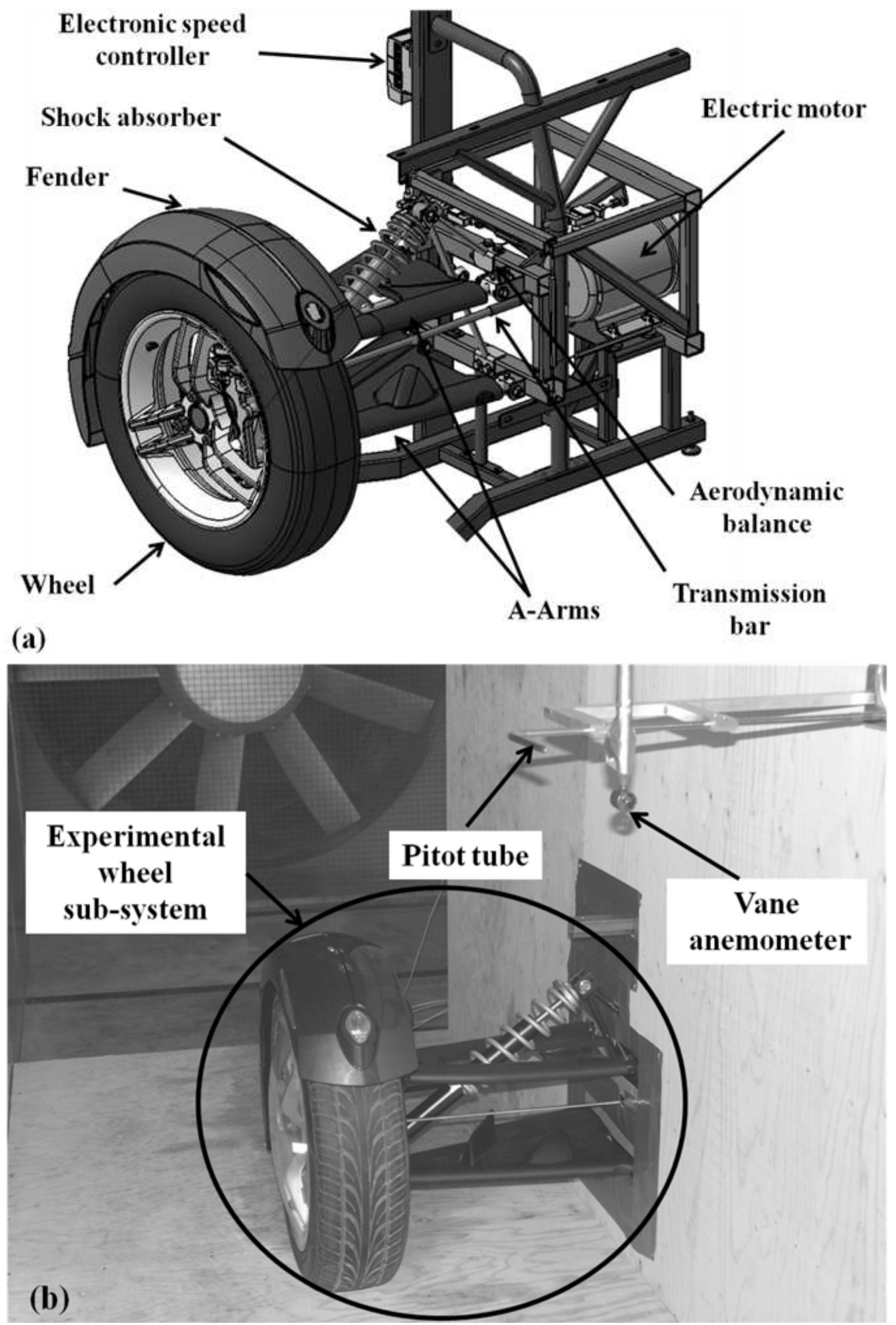

Fig 1 


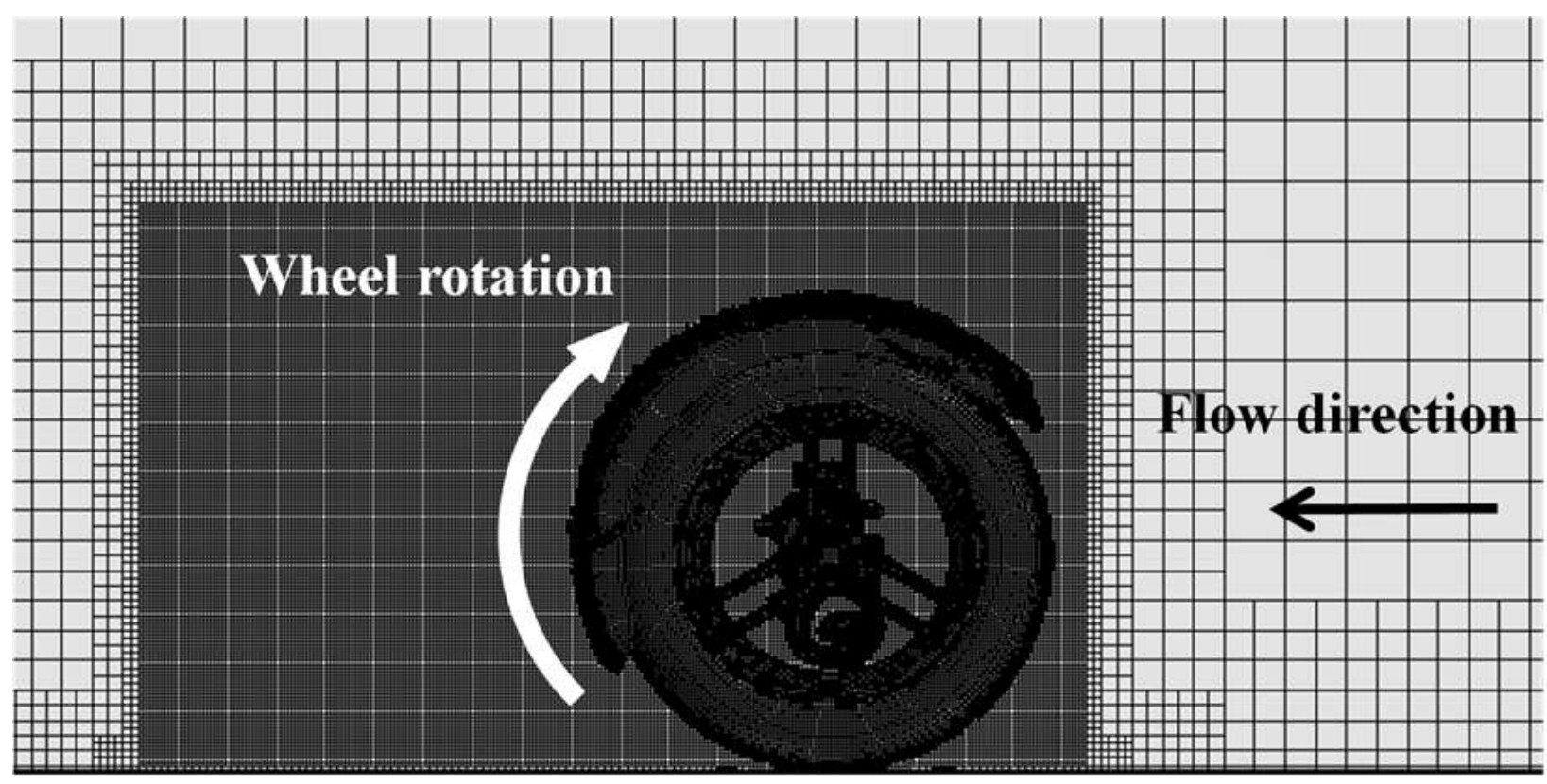

Fig 2

Hachimi Fellouah 


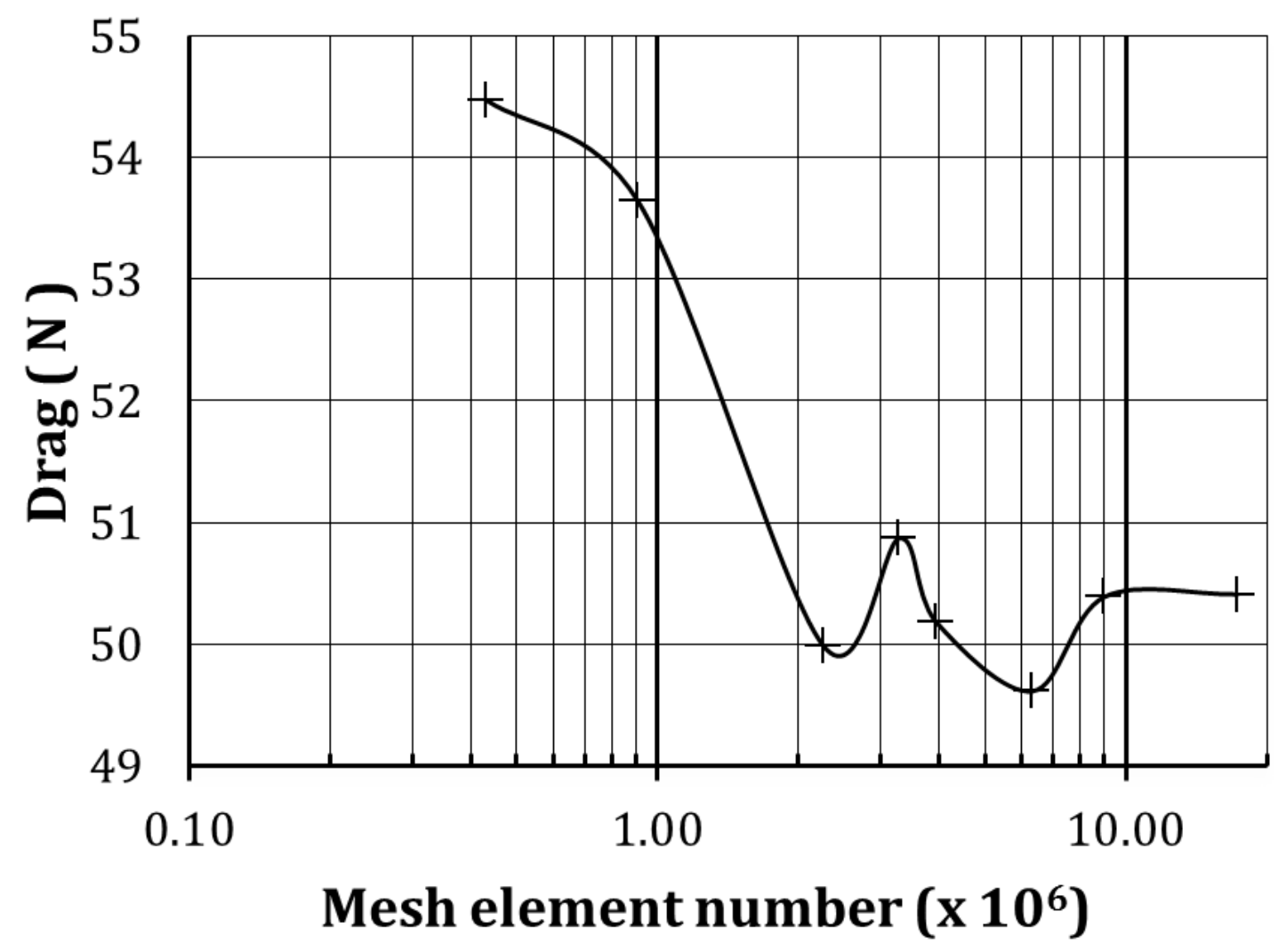

Fig 3 




Fig 4 


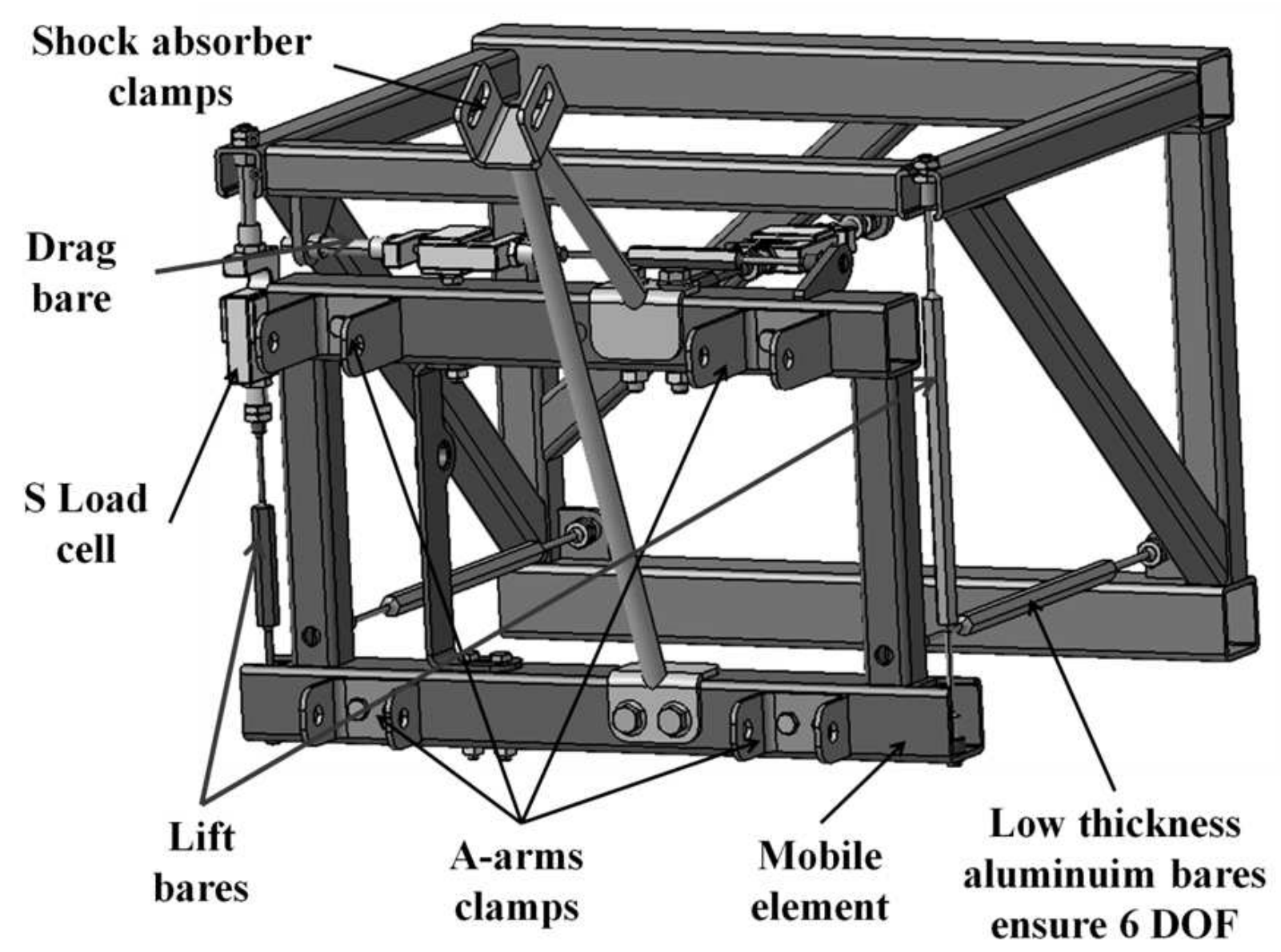

Fig 5 

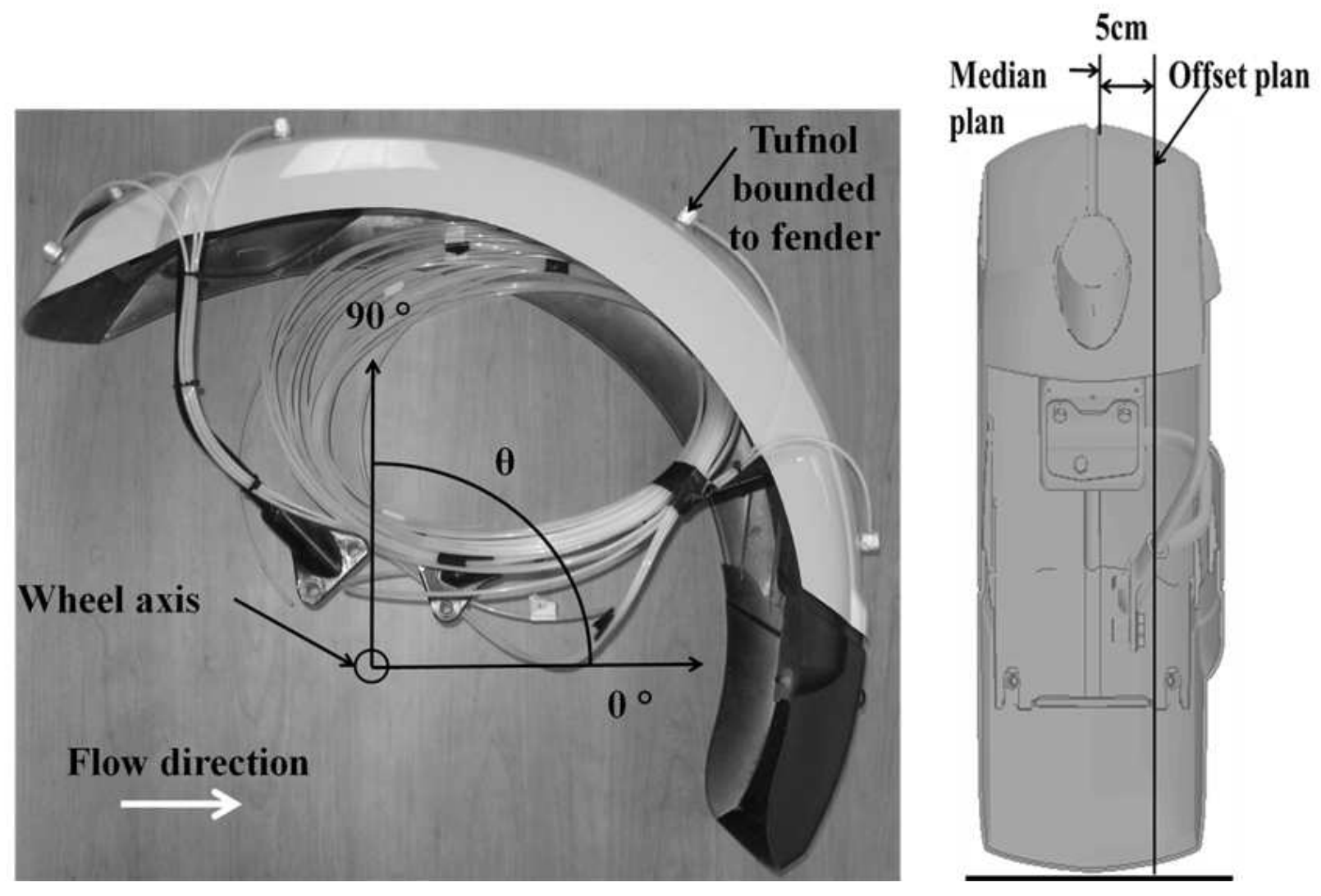

Fig 6 


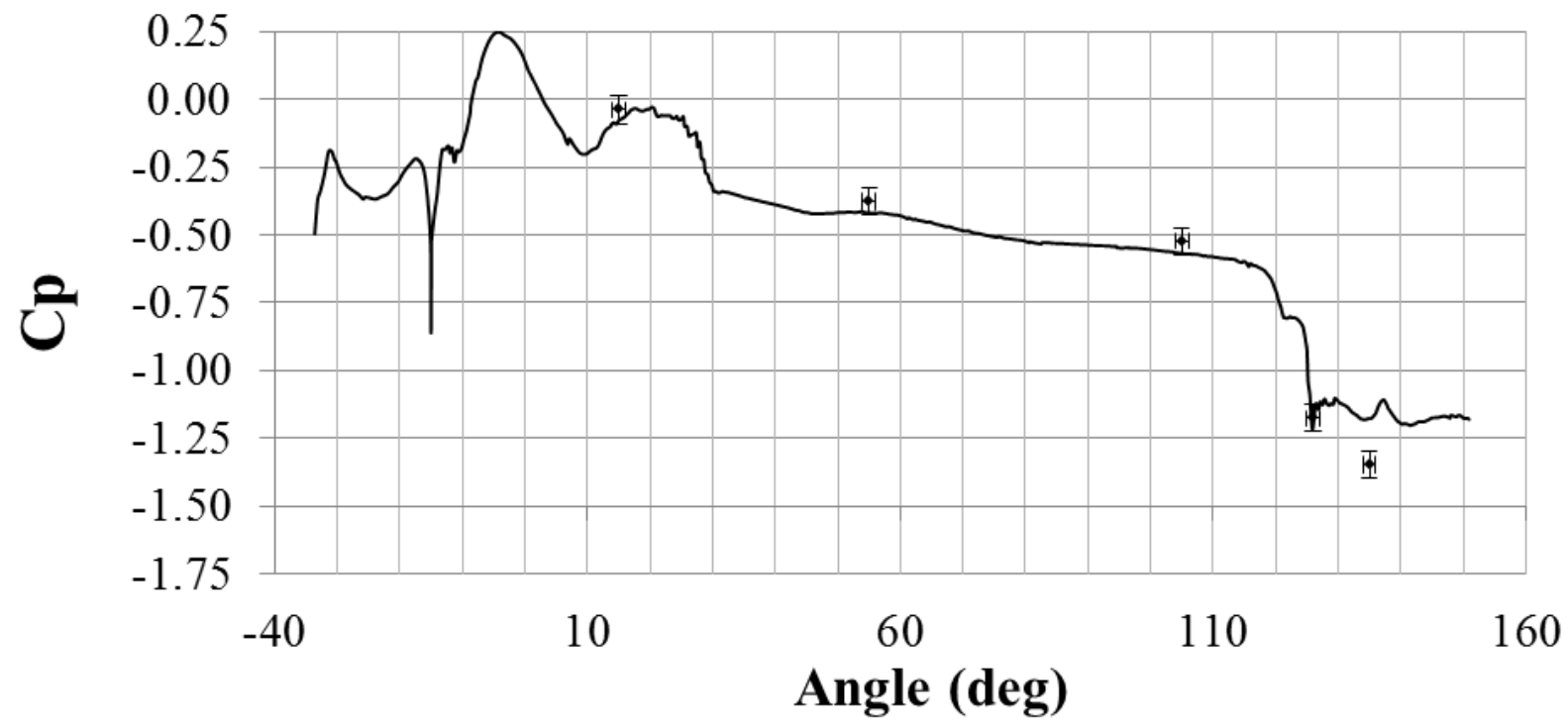

(a)

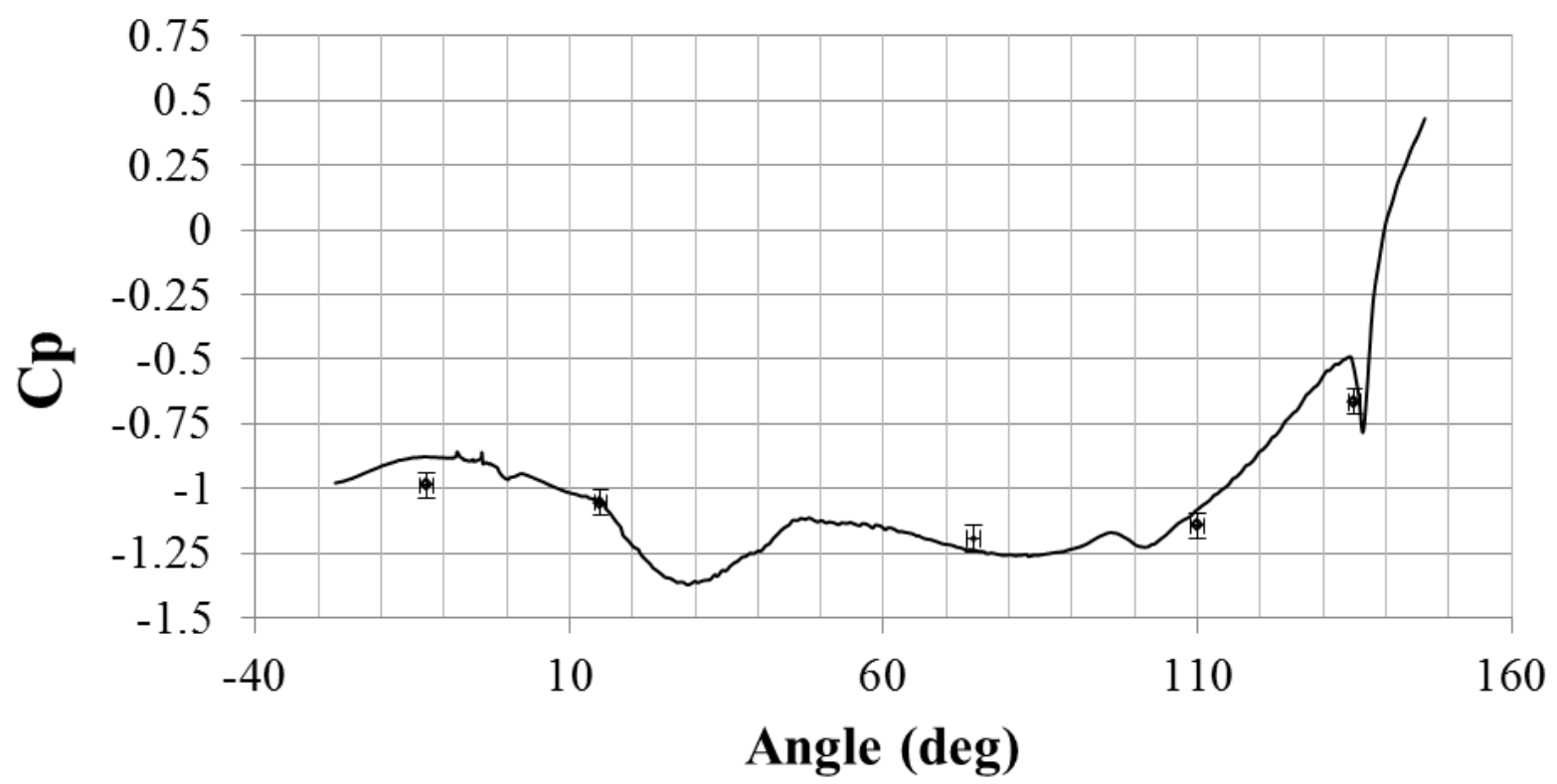

(b)

Fig 7 


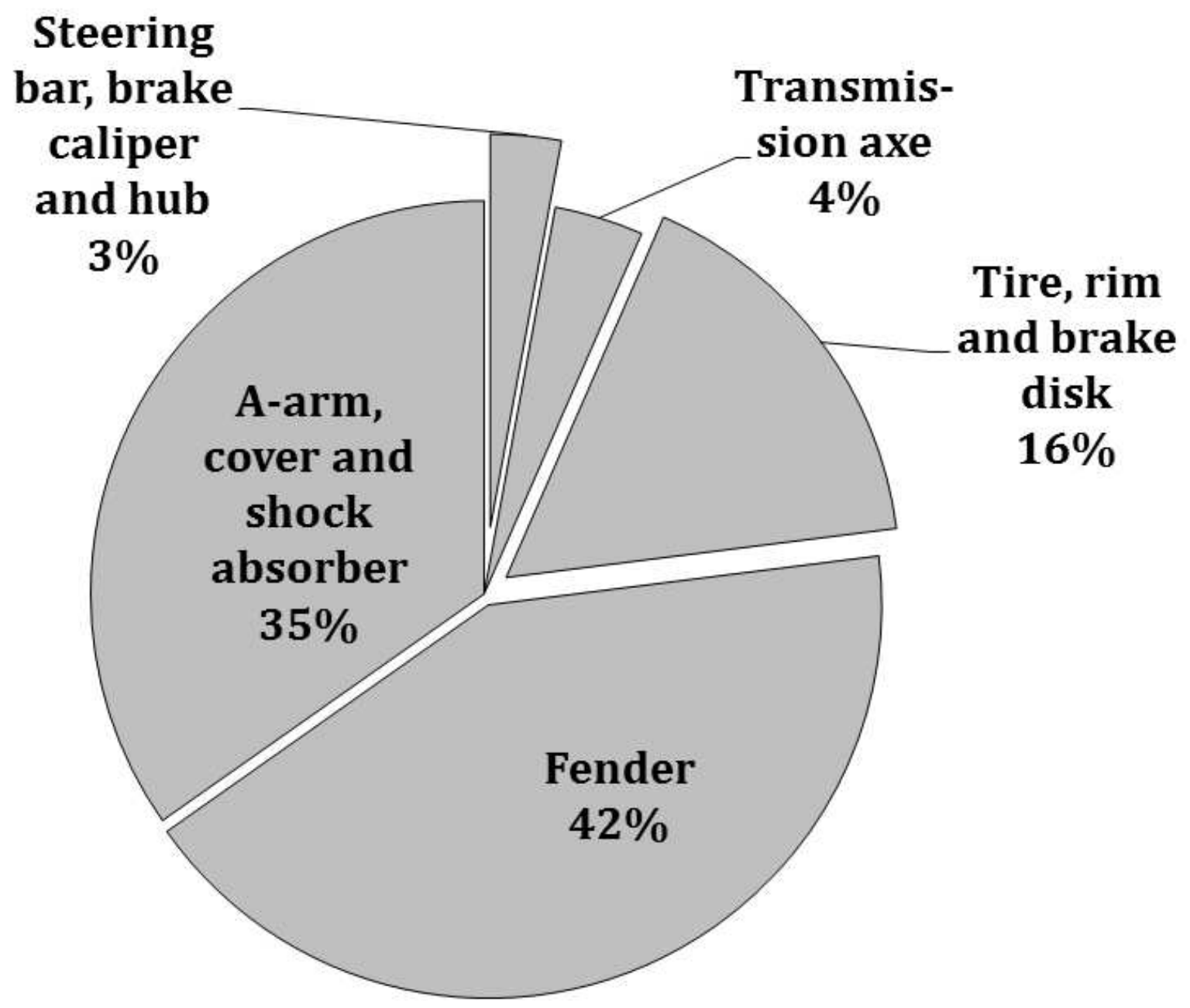

Fig 8 


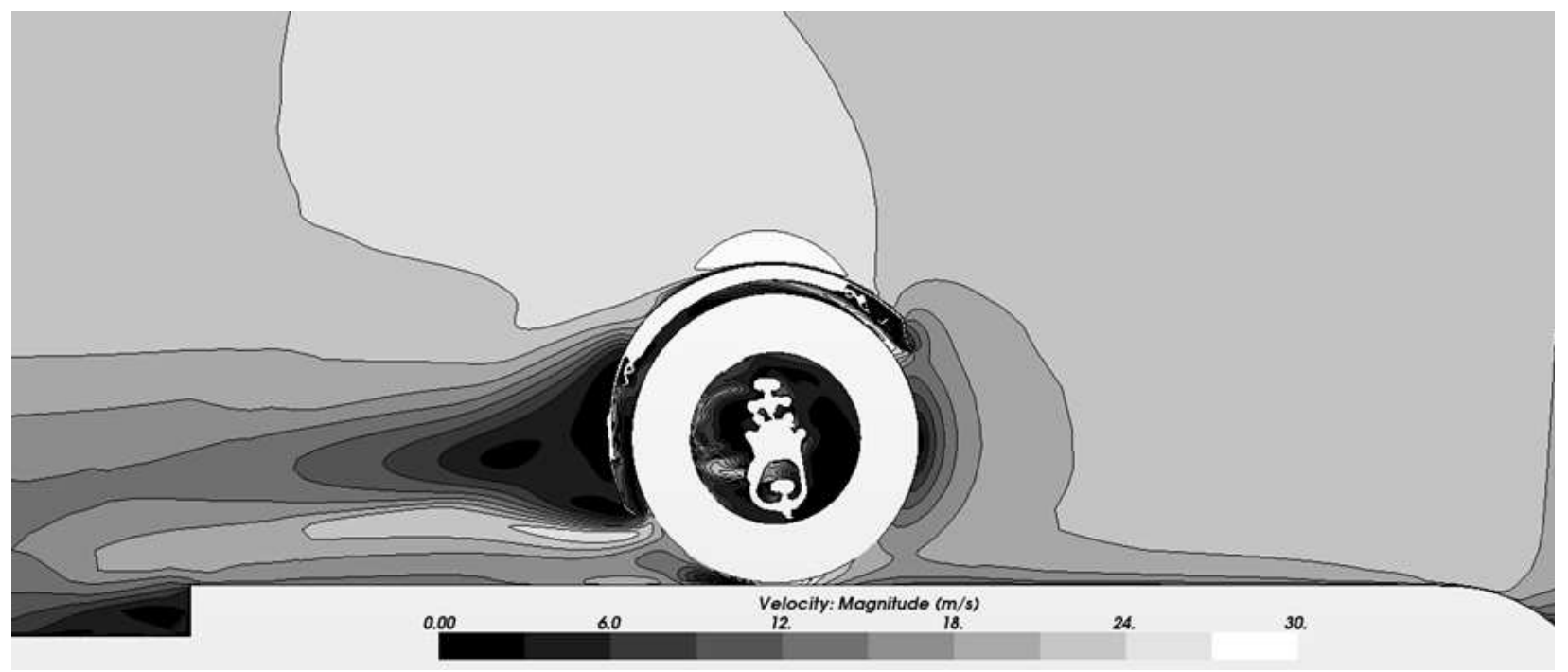

Fig 9 


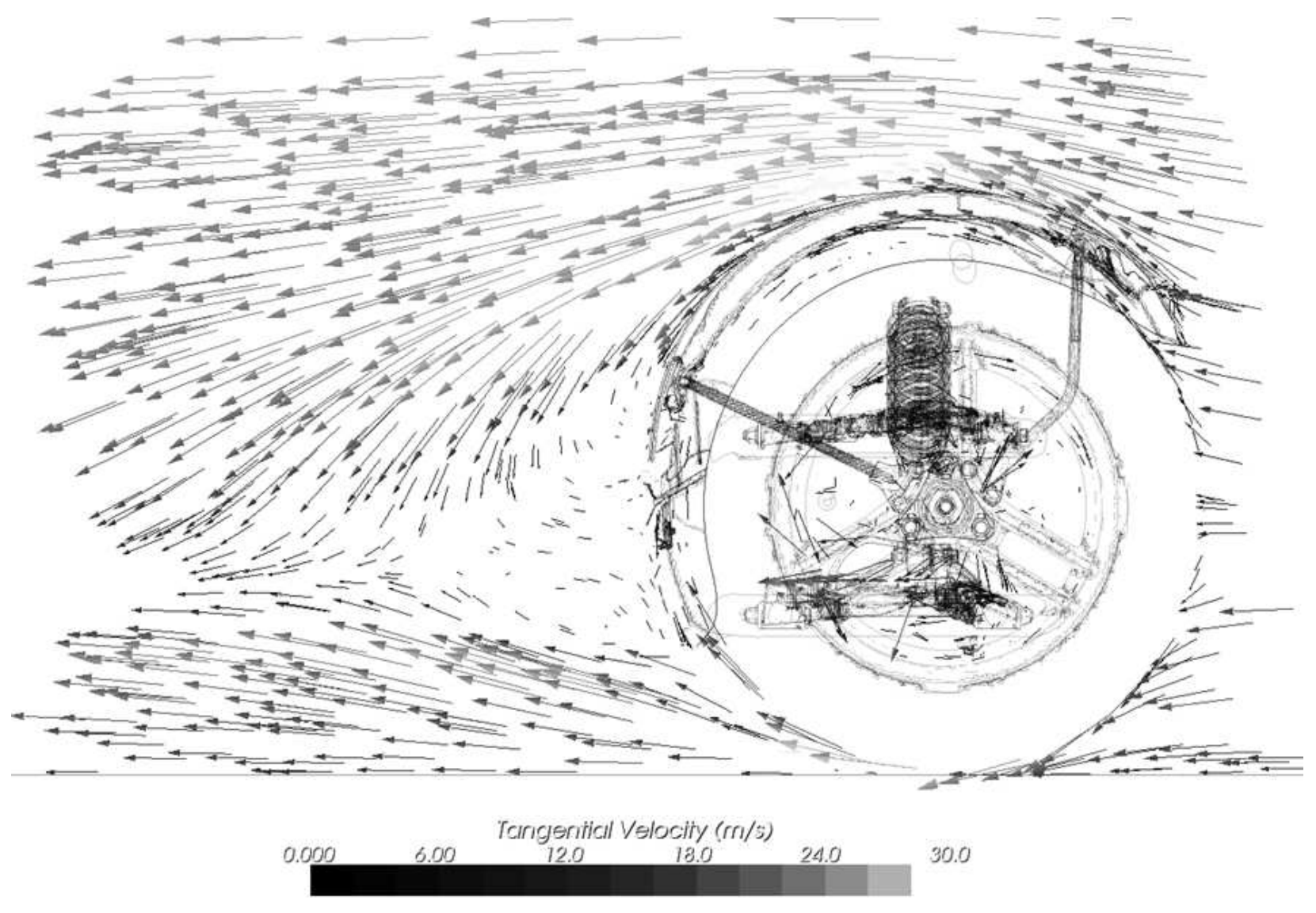

Fig 10

Hachimi Fellouah 




Fig 11

Hachimi Fellouah 


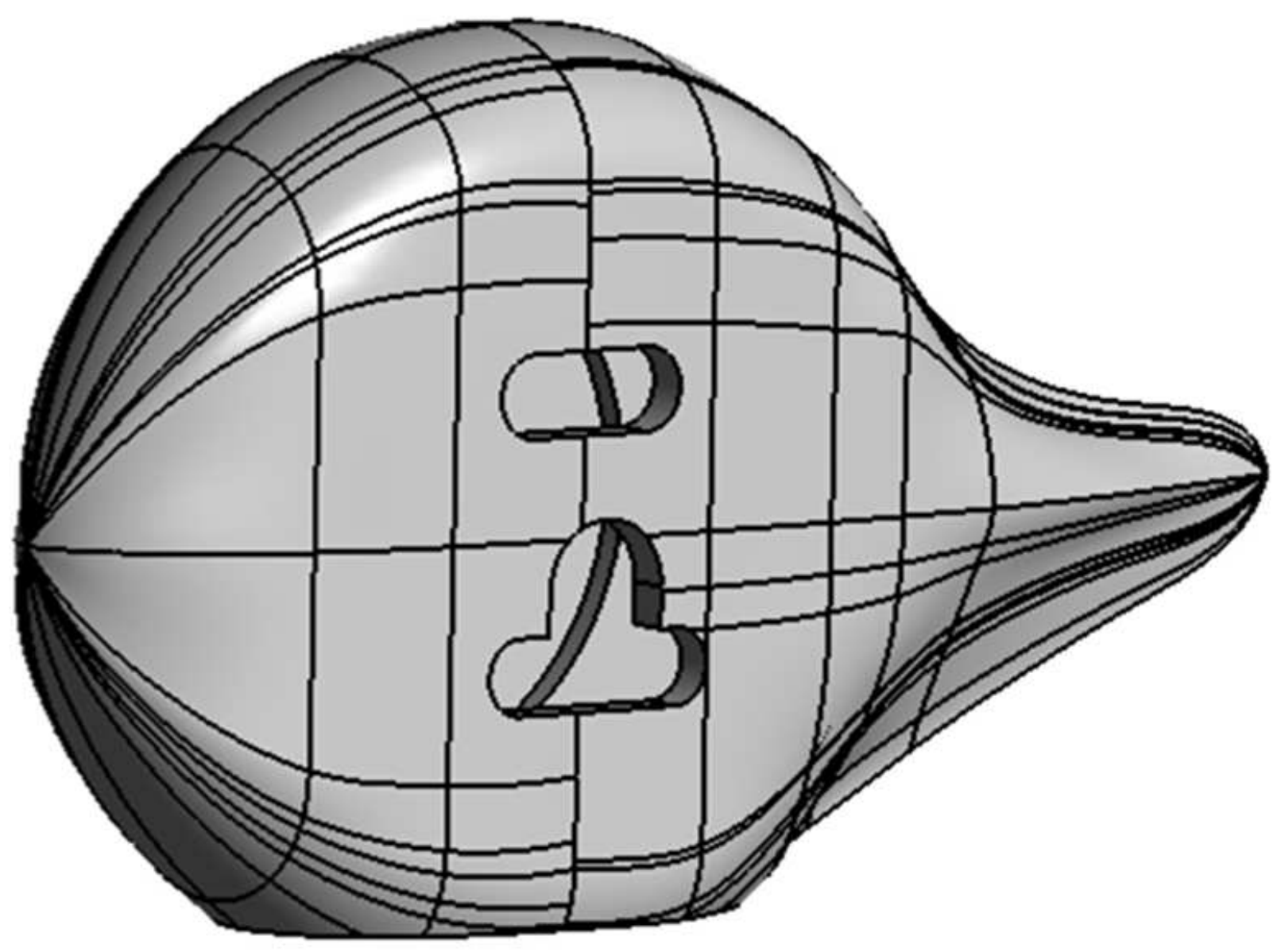

Fig 12

Hachimi Fellouah 


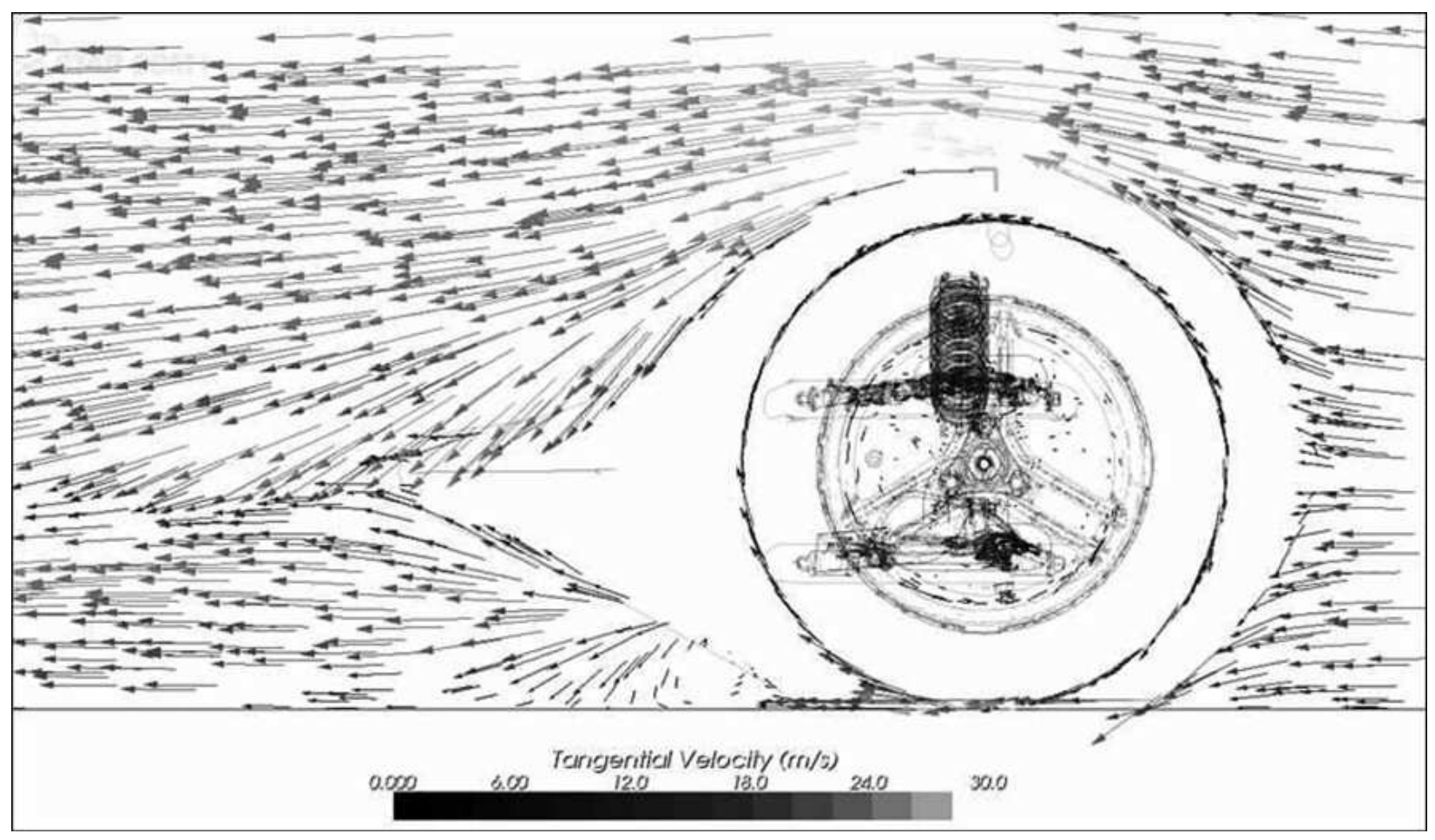

Fig 13

Hachimi Fellouah 




Fig 14 


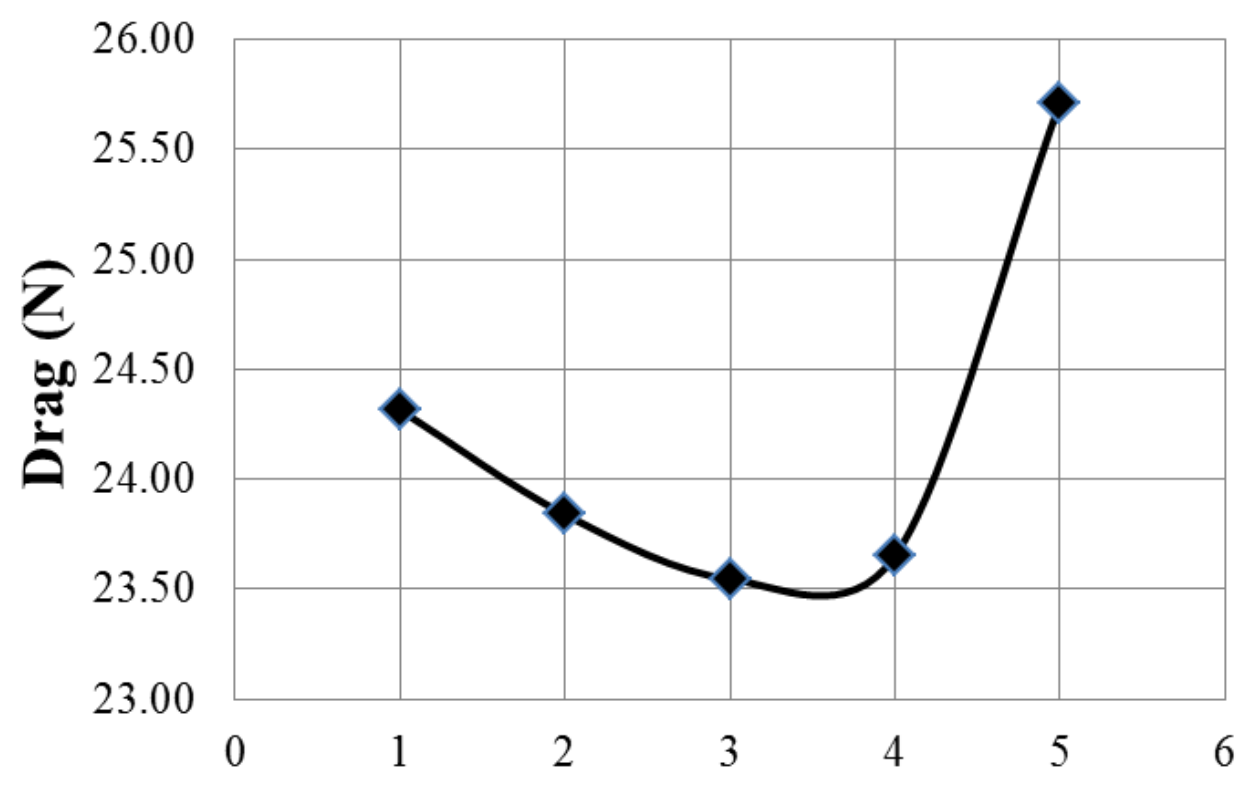

Horizontal cut

(a)

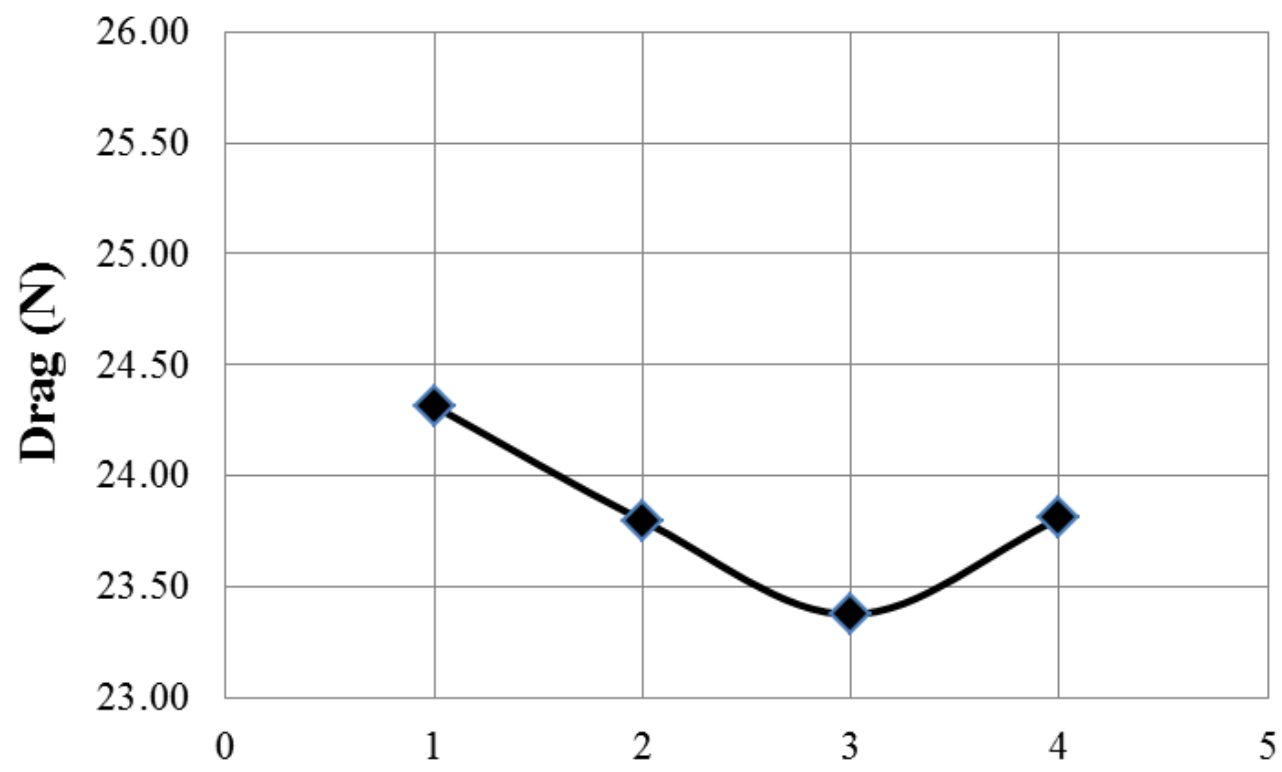

Vertical cut

(b)

Fig 15 

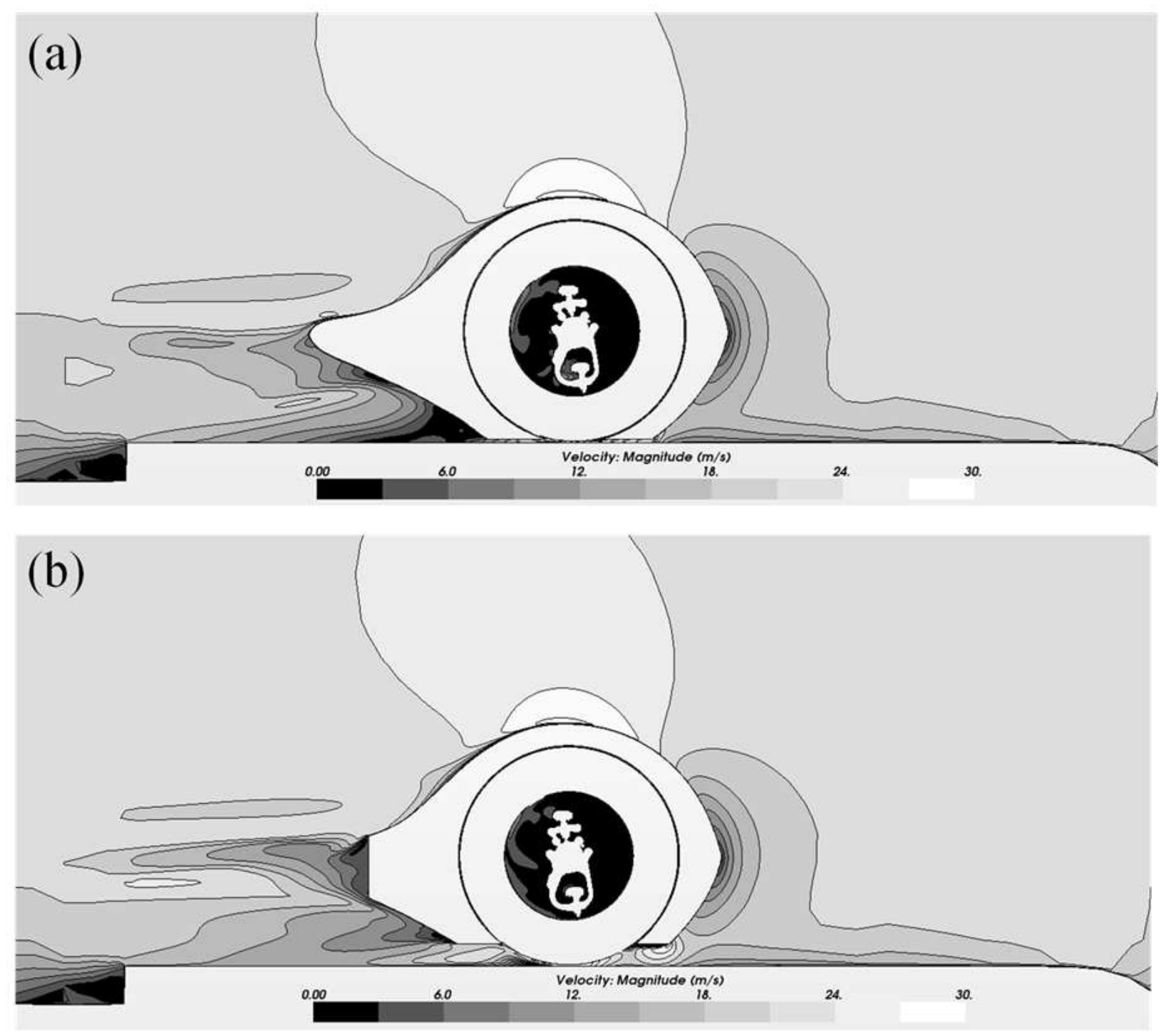

Fig 16 


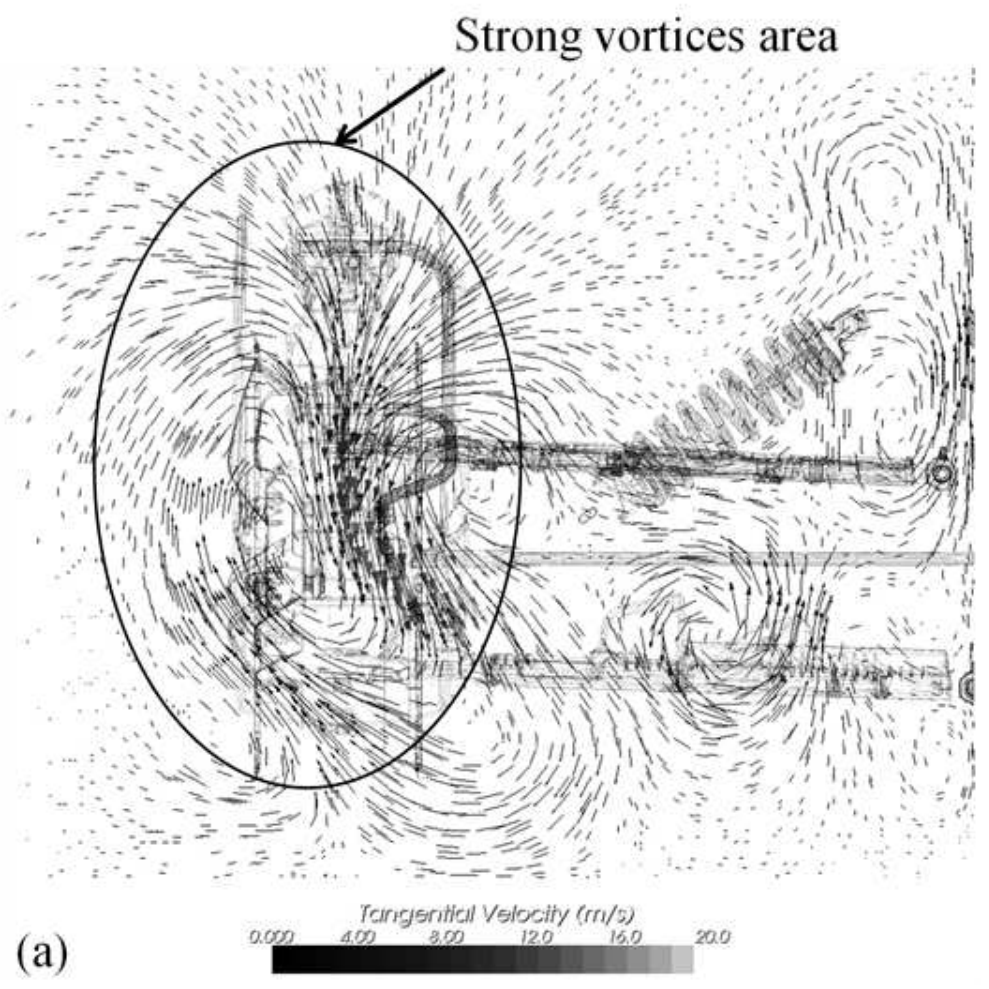

\section{Sensible reduction of the vortices area}



Fig 17

Hachimi Fellouah 